\title{
BMJ Open Understanding determinants of unequal distribution of stillbirth in Tehran, Iran: a concentration index decomposition approach
}

\author{
Amir Almasi-Hashiani, ${ }^{1}$ Mahdi Sepidarkish, ${ }^{1}$ Saeid Safiri, ${ }^{2}$ \\ Esmaeil Khedmati Morasae, ${ }^{3}$ Yahya Shadi, ${ }^{4}$ Reza Omani-Samani ${ }^{1}$
}

To cite: Almasi-Hashiani A, Sepidarkish M, Safiri S, et al. Understanding determinants of unequal distribution of stillbirth in Tehran, Iran: a concentration index decomposition approach. BMJ Open 2017;7:e013644. doi:10.1136/ bmjopen-2016-013644

Received 29 July 2016 Revised 15 February 2017 Accepted 20 February 2017

\section{CrossMark}

${ }^{1}$ Department of Epidemiology and Reproductive Health, Reproductive Epidemiology Research Centre, Royan Institute for Reproductive Biomedicine, ACECR, Tehran, The Islamic Republic of Iran

${ }^{2}$ Managerial Epidemiology Research Center, Department of Public Health, School of Nursing and Midwifery, Maragheh University of Medical Sciences, Maragheh, The Islamic Republic of Iran

${ }^{3}$ Centre for Systems Studies Hull University Business

School(HUBS), Hull York Medical School(HYMS), University of Hull, Hull, UK

${ }^{4}$ Department of Public Health, School of Public Health, Zanjan University of Medical Sciences, Zanjan, The Islamic Republic of Iran

Correspondence to Dr Reza Omani-Samani; r.samani@gmail.com

\section{ABSTRACT}

Objective The present inquiry set to determine the economic inequality in history of stillbirth and understanding determinants of unequal distribution of stillbirth in Tehran, Iran.

Methods A population-based cross-sectional study was conducted on 5170 pregnancies in Tehran, Iran, since 2015. Principal component analysis (PCA) was applied to measure the asset-based economic status. Concentration index was used to measure socioeconomic inequality in stillbirth and then decomposed into its determinants. Results The concentration index and its $95 \% \mathrm{Cl}$ for stillbirth was $-0.121(-0.235$ to -0.002$)$. Decomposition of the concentration index showed that mother's education (50\%), mother's occupation (30\%), economic status $(26 \%)$ and father's age $(12 \%)$ had the highest positive contributions to measured inequality in stillbirth history in Tehran. Mother's age (17\%) had the highest negative contribution to inequality.

Conclusions Stillbirth is unequally distributed among Iranian women and is mostly concentrated among low economic status people. Mother-related factors had the highest positive and negative contributions to inequality, highlighting specific interventions for mothers to redress inequality.

\section{INTRODUCTION}

A stillbirth is defined as a baby born with no signs of life at or after 28 weeks' gestation. ${ }^{1}$ Stillbirth is classified as either early (between 20 and 27 completed weeks of pregnancy), late (between 28 and 36 completed pregnancy weeks) or term (between 37 or more completed pregnancy weeks). ${ }^{2}$ Also, stillbirth is defined as fetal loss in the third trimester ( $\geq 28$ completed weeks of gestational age or $\geq 1000 \mathrm{~g}$ birth weight). ${ }^{3}$

Even with increasing concentration for maternal neonatal health, stillbirths remain as one of the main health issues worldwide. As a minimum, 2.65 million stillbirths (ranging from 2.08 million to 3.79 million) were estimated worldwide in 2008. Most cases of stillbirths (98\%) occur in low-income

\section{Strengths and limitations of this study}

- The present study measured economic status using more accurate (asset-based) method compared with other studies that use household income method. This method has fewer limitations compared with income method in developing countries.

- Instead of using linear regression to decompose inequality in a non-linear setting, the present study applied a more proper method to perform its objective.

- Due to the cross-sectional design of the study, causal interpretations of the findings were done with caution, and longitudinal studies were needed to evaluate the temporality of the presented associations.

- In addition, a self-administered questionnaire was applied, and some information biases were induced. Also, due to lack of data in some categories, especially for some combination of exposure and outcome levels, sparse data bias may have occurred.

- The current socioeconomic status was used as proxy of socioeconomic status in the near past (during the stillbirth), which could be changed partially.

and middle-income countries. The lowest numbers were reported from Finland (two cases per 1000 total births), and the highest numbers were reported in Nigeria and Pakistan (more than 40 cases per 1000 total births). ${ }^{3}$ Based on the report of WHO, for every 1000 total births, 18.4 babies were stillborn, mostly in low-income countries and middle-income countries worldwide in $2015 .{ }^{4}$

Numerous factors are related with stillbirth including maternal infections, non-communicable diseases, nutrition, lifestyle-related factors and maternal age. Fourteen per cent of stillbirths contribute to prolonged pregnancies. ${ }^{5}$ Some studies show that economic status is one of the main causes of prenatal outcomes especially stillbirth, ${ }^{6-9}$ and the rate of stillbirth was more concentrated in low economic area. 
The rates of preterm birth and stillbirth diverge in countries and by sociodemographic variables. ${ }^{10}$ The highest stillbirth rate, neonatal mortality rate and intrapartum-related mortality rates occur in areas with low socioeconomic status due to accessing care in rural areas, emergency obstetric care, immediate postnatal and prenatal care, gaps in healthcare coverage during the prenatal, intrapartum and postnatal periods skilled birth attendance. ${ }^{11}{ }^{12}$ Disparities in these rates are obvious. Even in areas with high income, there are inequalities in stillbirth rates; for instance in the UK, black women are two times more prone to have a stillbirth than white women. ${ }^{3} 13$

Iran is a developing country located in Asia. Based on the 2010 report, $96.42 \%$ of deliveries were done in presence of skilled health workers, and maternity care coverage during pregnancy was reported $96.92 \%$.

The cause of a large proportion of stillbirths is unknown, and some studies are needed to determine the cause of unexplained stillbirth. ${ }^{14}$ Therefore, the present study aimed to determine the economic inequality in history of stillbirth and understanding determinants of unequal distribution of stillbirth in Tehran, Iran.

\section{METHOD}

Although the methodology of this study was described elsewhere, ${ }^{15}$ here, more detailed information is reported on inequality analysis. A population-based cross-sectional study was conducted, which was a part of large survey on twin and multiple pregnancies in Tehran Province, Iran. Data collected were related to 5170 deliveries between 6 July and 21 July 2015 in 103 government, private and military hospitals to ensure women with broad range of socioeconomic status. The data were gathered from medical centres with obstetrics and gynaecology wards. All women regardless of the type of delivery (natural or caesarean section) and pregnancy outcome (live birth, stillbirth and spontaneous abortion) were included in the study. Also, the unstable women filled out the questionnaire after 2 or 3 days. The sampling procedure was carried out for 2 weeks. This report STROBE guideline.

Validity indices of questionnaire including face validity, relevancy, clarity, comprehensiveness and inter-rater agreement were reported above the acceptable level of $80 \%$. One hundred and three educated midwives as interviewers completed the questionnaire. If participants had not been aware of variables studied, their medical records would have been observed or would have conducted interviews with obstetricians and nurses. The outcomes of interest were history of stillbirth, and economic status was considered an independent variable. Economic status of participants was measured based on 'asset base method', in which the pregnant women were asked about their assets including vacuum cleaner, handicraft carpet, laptop, freezer, dish washing machines, private cars, touch mobile, three-dimensional TV, side-by-side refrigerator, microwaves, number of rooms and area of residence.
This study was approved in 2015 by the Ethical Committee of Royan Institute, Tehran, Iran (ethical code: 91000357). At the beginning of the study, the study's aims were clearly presented for all participants. Confidentiality and anonymity of eligible individuals were assured; they were informed that they could withdraw at any phase of the study. Verbal informed consent was obtained from all subjects before the study.

\section{METHODOLOGY}

Independent variables (determinants) of the study were as follows: mother's and father's age, nationality (Iranian and non-Iranian), education, occupation and household economic status. Age was categorised into two groups: over and under 35 years old. There were three categories for education: under diploma, diploma (end of high school) and academic degrees. Father's occupation included the following categories: professional, managerial and technical, skilled non-manual, skilled manual, partly skilled and unskilled occupations. Unequal distribution of history of stillbirth was considered as a main outcome. Stillbirth was defined as a baby born with no signs of life at or after 28 weeks' gestation. ${ }^{16}$

To measure the economic status of households, principal component analysis (PCA) method was used. PCA, basically, is a standard factor analysis method leading to reduction of a slew of (asset) variables into one variable (ie, economic status variable indicating the economic position of households). Asset variables used in the study for PCA were as follows: the number of rooms per person, area per capita, possession of automobile, carpet, microwave, dishwasher, TV, freezer, refrigerator, vacuum cleaner, laptop, PC, washing machine and cell phone. Categorical variables should change to binary variables (have or not-have) before running a PCA. Numeric variables, however, do undergo no change (ie, area per capita and the number of rooms per person). PCA result is a number of components on which asset variables are loaded. However, only the first component represents the economic status of the households as it can explain a remarkable part of variance (32\% in our study) in economic status. In fact, economic status is the first component of PCA that is able to distinguish between people in terms of their economic status. The asset variables that are loaded on the first component and give such a distinguishing ability to it were as follows: refrigerator, dishwasher, laptop and microwave. An economic score was, finally, determined for each household by PCA. Then, the households were economically ranked, and economic quintiles were constructed to be used in the subsequent modelling. ${ }^{17}$

Concentration curve and index were used to measure and decompose socioeconomic inequality in stillbirth history. ${ }^{18-20}$ The two key variables constructing the concentration curve were the stillbirth history, its distribution, economic status variable, against which the distribution is assessed. Concentration curve plots the 
cumulative percentage of the stillbirth history (y-axis) against the cumulative percentage of the sample ranked by economic status, starting from the poorest (x-axis). If everyone, irrespective of his or her economic status, has exactly the same history of stillbirth, the concentration curve will be a $45^{\circ}$ line, running from the bottom lefthand corner to the top right-hand corner. This is known as the line of equality. If, in contrast, stillbirth history takes higher values among poorer people, the concentration curve will lie above the line of equality and vice versa. Concentration index reports the distance between the concentration curve and the line of equality. Concentration index ranges from -1 to +1 , with negative values indicating that the concentration curve lies above the line of equality and vice versa.

Wagstaff et al demonstrated that a concentration index can be decomposed into contributions of different explanatory factors to inequality. ${ }^{18-20}$ In fact, for any linear (regression) model of health, such as

$$
\gamma i=\alpha+\sum_{k} \beta_{k} x_{k i}+\epsilon_{i}
$$

the concentration index (C) for y (stillbirth history) can be written as:

$$
C=\sum_{k}\left(\frac{\beta_{k} \bar{x}_{k}}{\mu} C_{k}\right)+\frac{\mathrm{G} C_{\epsilon}}{\mu}=C \gamma+\frac{\mathrm{G} C_{\epsilon}}{\mu}
$$

where $\mu$ is the mean of $y$; $X_{k}$ is the mean of factors; $C_{k}$ is the concentration index for factors and $\mathrm{GC}_{\varepsilon}$ is the generalised concentration index for the error term $(\varepsilon)$.

However, as the health variable is a dichotomous variable in the present study and it has no linear probability distribution but only when it changes to natural logarithm (Ln), $\mu$ in the formula (2) will change to $\operatorname{Ln}$ of $\mu$.

There are two parts in formula (2): $\mathrm{GC}_{\varepsilon}$ or residual component that reflects the part of inequality in stillbirth history that cannot be explained by systematic variation in the factors. Explained component $\left(C_{\gamma}\right)$ that shows the contributions of explanatory factors to inequality. Each contribution is the product of sensitivity or relationship (elasticity) of stillbirth history with factor $\beta_{k} \bar{x}_{k} / \mu$ and the degree of economic inequality in factor $\left(C_{k}\right)$.

\section{RESULTS}

Table 1 illustrates the demographic features of subjects studied. As the table shows, most of subjects, male or female, were under 35 years of age, Iranian and had a diploma degree. In terms of occupation, $87.5 \%$ of women were housewives, and $50.51 \%$ of men belonged to 'unskilled' and 'partly-skilled' occupations. In terms of stillbirth history, $2 \%$ of subjects had such a history.

Figure 1 depicts stillbirth history concentration curve; the curve is above the equality line and indicates that stillbirth is more concentrated among lower economic status people in Tehran. This shows that there is inequality in distribution of stillbirth in Tehran, and the inequality disfavours the poor. Size of the inequality that equals history of stillbirth concentration index equals -0.121 ( $95 \%$ C I -0.235 to -0.001 ).

Table 2 shows the logistic regression analysis results for stillbirth history and its determinants. As the table shows, there is a significant relationship between lower economic status, mother's age (15-25) and odds of stillbirth history. However, there is no significant relationship between other variables and stillbirth history.

Interestingly, there was no significant inequality in distribution of pre-eclampsia -0.008 (95\% CI -0.078 to 0.060 ), abortion 0.021 (95\% CI -0.010 to 0.052$)$, weight at birth $(\mathrm{kg})$ for the last child -0.001 (95\% CI -0.004 to $0.0009)$ and stillbirth in the last pregnancy 0.103 (95\% CI -0.055 to 0.264 ) in Tehran.

Since coefficients of occupation groups were so close to each other, they were recategorised into three occupation groups: professional (professional, managerial and technical), skilled (skilled non-manual and skilled manual) and unskilled (partly skilled and unskilled).

Table 3 illustrates the results for decomposition of inequality in stillbirth. Mother's education $(50 \%)$, mother's occupation (30\%), economic status $(26 \%)$ and father's age $(12 \%)$ had the highest positive contribution to measured inequality in stillbirth history, respectively. Interestingly, mother age (17\%), belonging to non-Iranian nationalities, had negative contribution to inequality, that is, they decreased from inequality size in stillbirth in Tehran.

\section{DISCUSSION}

To the best of our knowledge, several studies have been conducted on the prevalence and risk factors affecting stillbirth, but few studies were done regarding socioeconomic factors influencing the stillbirth rate. Among these studies, even in developed countries, there are few researches on the impact of socioeconomic inequality on stillbirth. ${ }^{21}{ }^{22}$ In the present study, for the first time, the socioeconomic inequality in stillbirth in Iran's capital, Tehran, was explained via adopting a CI decomposition approach. This approach can help us to find the main causes of socioeconomic inequalities in stillbirth, which will be vital for policymakers in its prevention.

The stillbirth CI (of Ln odds stillbirth$_{\text {) }}$ ) revealed that stillbirth is unequally distributed among study subjects. In fact, the negative value of CI indicates that stillbirth is disproportionately concentrated among people of lower socioeconomic status. This finding has been approved by some other studies in developed and developing countries. ${ }^{23}{ }^{24}$ This propoor inequality exists within countries and this pattern could be extrapolated between countries; a global study found that $98 \%$ of all stillbirths occur in low-income and middle-income countries, while $77 \%$ in south Asia and sub-Saharan Africa.

Moreover, decomposition of stillbirth inequality showed that all independent variables (except mother's nationality, mother's age and father's age) have positive contributions to socioeconomic inequality in stillbirth. 
Table 1 Demographic features of subjects participated in study in Tehran in 2014

\begin{tabular}{|c|c|c|c|}
\hline & Variable & Frequency & Per cent (\%) \\
\hline \multirow[t]{3}{*}{ Mother's age } & $15-25$ & 1344 & 26.25 \\
\hline & $26-35$ & 3457 & 61.66 \\
\hline & $>36$ & 619 & 12.09 \\
\hline \multirow[t]{3}{*}{ Father's age } & $15-25$ & 332 & 6.52 \\
\hline & $26-35$ & 3045 & 59.83 \\
\hline & $>36$ & 1712 & 33.64 \\
\hline \multirow[t]{2}{*}{ Mother's nationality } & Iranian & 4794 & 92.98 \\
\hline & Non-Iranian & 362 & 7.02 \\
\hline \multirow[t]{2}{*}{ Father's nationality } & Iranian & 4773 & 92.91 \\
\hline & Non-Iranian & 364 & 7.09 \\
\hline \multirow[t]{3}{*}{ Mother's education } & Under diploma & 1416 & 27.52 \\
\hline & Diploma & 2062 & 40.08 \\
\hline & Academic & 1667 & 32.4 \\
\hline \multirow[t]{3}{*}{ Father's education } & Under diploma & 1689 & 32.87 \\
\hline & Diploma & 1825 & 35.52 \\
\hline & Academic & 1624 & 31.61 \\
\hline \multirow[t]{6}{*}{ Father's occupation } & Professional occupations & 88 & 1.72 \\
\hline & Managerial and technical occupations & 236 & 4.61 \\
\hline & Skilled non-manual occupations & 1344 & 26.26 \\
\hline & Skilled manual occupations & 865 & 16.9 \\
\hline & Partly skilled occupations & 1600 & 31.26 \\
\hline & Unskilled occupations & 985 & 19.25 \\
\hline \multirow[t]{2}{*}{ Mother's occupation } & Housewife & 4509 & 87.5 \\
\hline & Employed & 644 & 12.5 \\
\hline \multirow[t]{5}{*}{ Economic status } & Most deprived & 1009 & 20.01 \\
\hline & Quintile 2 & 1011 & 20.05 \\
\hline & Quintile 3 & 1006 & 19.95 \\
\hline & Quintile 4 & 1008 & 19.99 \\
\hline & Least deprived & 1008 & 19.99 \\
\hline \multirow[t]{2}{*}{ Stillbirth history } & Yes & 96 & 2 \\
\hline & No & 5071 & 98 \\
\hline \multirow[t]{2}{*}{ Pre-eclampsia history } & Yes & 252 & 4.88 \\
\hline & No & 4914 & 95.12 \\
\hline \multirow[t]{2}{*}{ Abortion history } & Yes & 1035 & 20.03 \\
\hline & No & 4133 & 79.97 \\
\hline \multirow[t]{2}{*}{ Stillbirth in the last pregnancy } & Yes & 53 & 1.04 \\
\hline & No & 5024 & 98.96 \\
\hline Weight at birth for the last child $(\mathrm{kg})$ & Mean (SD) & 4872 & $3188.6(\mathrm{SD}=503.2)$ \\
\hline
\end{tabular}

A positive contribution implies that the combined effect of the marginal effect of the desired determinant and its distribution based on economic status increase socioeconomic inequality in stillbirth. This can occur because either the desired determinant is more prevalent among people of lower economic status (negative $\mathrm{C}_{\mathrm{k}}$ ) and is associated with a higher risk of stillbirth or because the determinant is more prevalent among those of higher economic status (positive $\mathrm{C}_{\mathrm{k}}$ ) and is associated with a lower risk of stillbirth. Also, mother's education accounted for most of the socioeconomic inequality in stillbirth among Tehran's women. Indeed, mother education alone is responsible for $50 \%$ of the socioeconomic inequality in stillbirth history. The other determinants with relatively large positive contributions to socioeconomic inequality in stillbirth are mother's occupation 


\section{Concentration Curve}

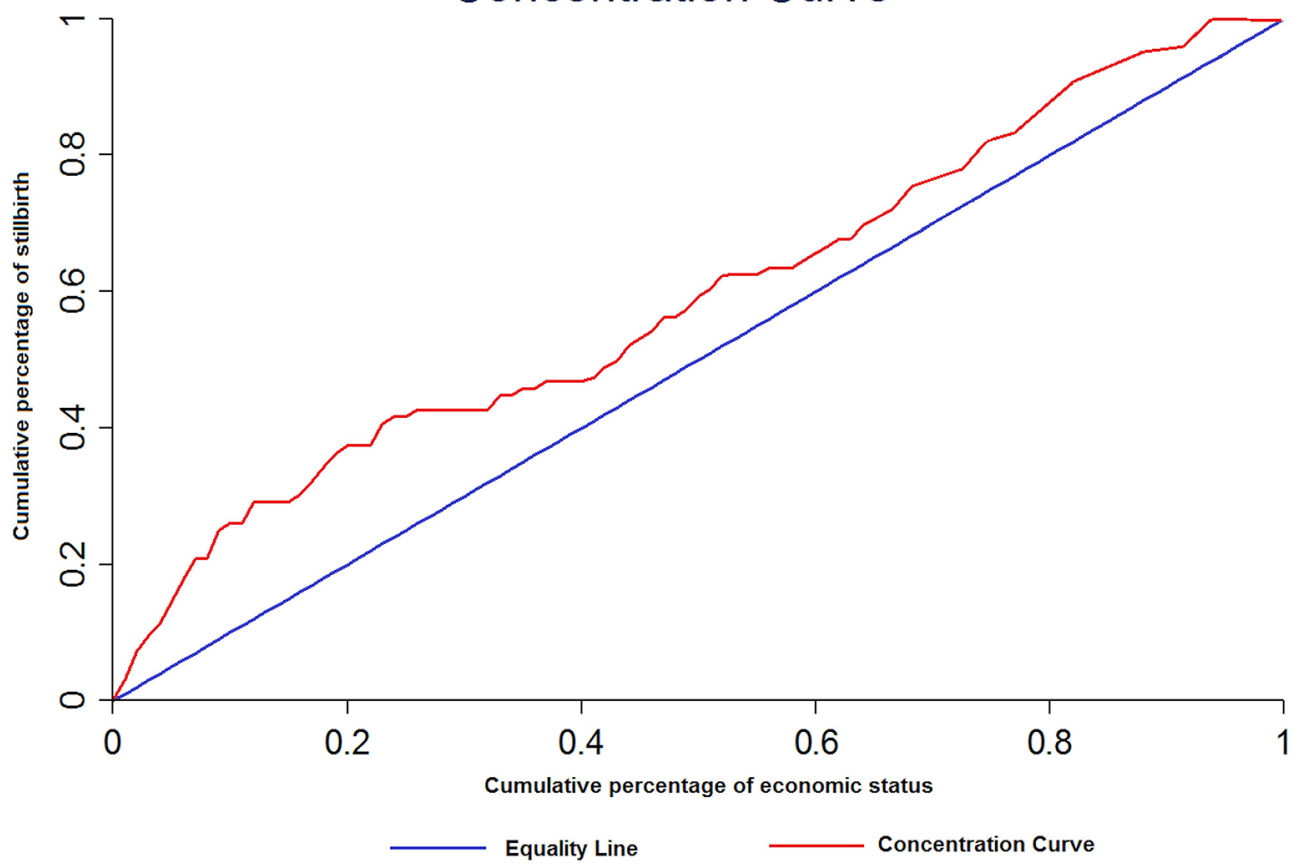

Figure 1 Concentration curve of stillbirth history in Tehran in 2014. Concentration index is the area between equality line and concentration curve that in the present study equalled: -0.121 .

$(30 \%)$, economic status (26\%) and father's age (12\%). Interestingly enough, mother's age (17\%), belonging to non-Iranian nationalities, had negative contribution to inequality, that is, they decreased from inequality size in stillbirth in Tehran.

The decomposition method helps to quantify the contributions of determinants to socioeconomic inequality in health-related problems. ${ }^{25}{ }^{26}$ However, analysis of studied determinants in this study showed that $26 \%$ of socioeconomic inequality can be explained by economic status, but $74 \%$ can be eliminated by managing other determinants such as mother's and father's education, employment, and more. Hence, decomposition is an important way to monitor and understand the determinants of inequality. ${ }^{25} 26$

When comparing the findings with other findings, the differences in calculation of economic status should be considered. Asset-based, consumption expenditure and income are the most popular measures for assessing the economic status. The asset-based method provides a rapid and simple method for collecting economic status data. Short interview time and questionnaire space are needed for this method. While the essential principles of analysis with PCA are complicated, their application is easy in many statistical packages. According to some evidence, the asset index is a more lasting measure of economic status than consumption expenditure, changing less in response to variations in income and expenditure and being resistant to most economic shocks. ${ }^{27}$ This may be particularly important in low-income and middle-income countries that may have greater fluctuations in consumption patterns than high-income countries. On the other hand, asset index data is more available in many studies that make the comparative research easier all over the world. However, as the asset index is a measure of relative economic status, the poorest category of one country could not be compared with corresponding category in other country. ${ }^{28}$

It is obvious that no previous studies have tried to address the issue of stillbirth inequality in a manner similar to the present study. The present study found that stillbirth is more concentrated among lower socioeconomic status people in Tehran, which is confirmed by some other studies. A systematic analysis on the national, regional and worldwide estimates of stillbirth rates in 2015 shows that $98 \%$ of all stillbirths occur in low-income and middle-income countries and $77 \%$ in south Asia and sub-Saharan Africa. ${ }^{24}$ Also, a review on the high-income countries found that a woman living under adverse socioeconomic circumstances has twice the risk of having a stillborn child when compared with her more advantaged counterparts. ${ }^{29}$ Also, another study on the trends in socioeconomic inequalities concerning the risk of sudden infant death syndrome, other causes of infant mortality and stillbirth in Scotland showed a significant negative association between the economic status and risk of stillbirths. ${ }^{30}$ These findings are also confirmed by another study on Swedish primiparous women, showing that low SES increases the risk of stillbirth. ${ }^{22}$

In the present study, decomposing socioeconomic inequality shows that although mother education per se is accounted for $50 \%$ of inequality in stillbirth history, the remaining inequality is explained by some determinants including mother's occupation and father's age which are 


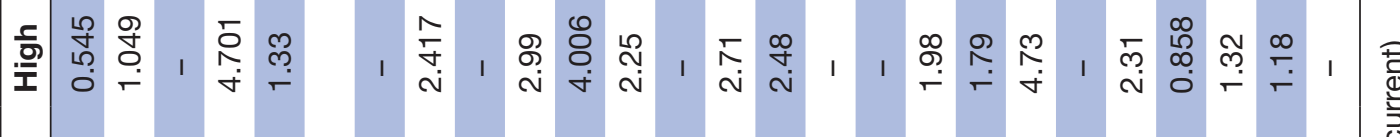

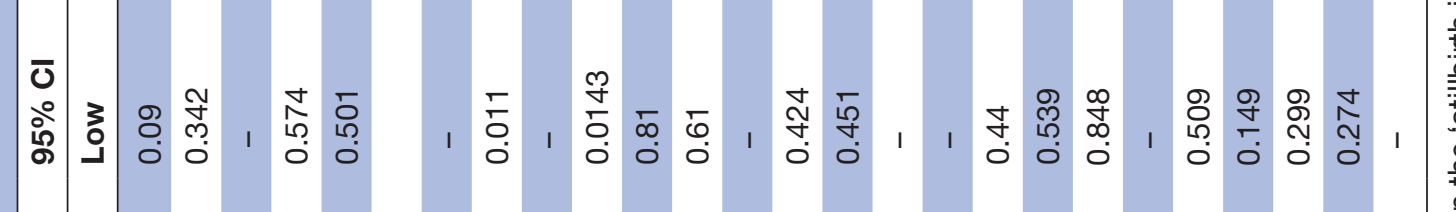

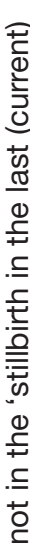

橆

寜

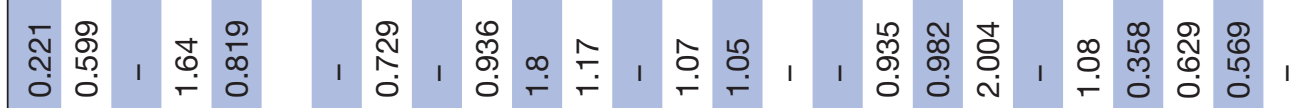

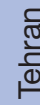

$\frac{0}{\frac{2}{\pi}}$

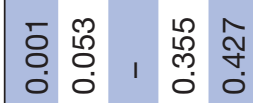

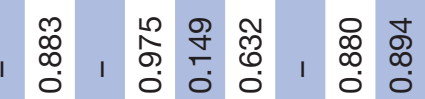

ஜु.

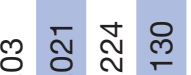

흥

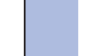

(1)

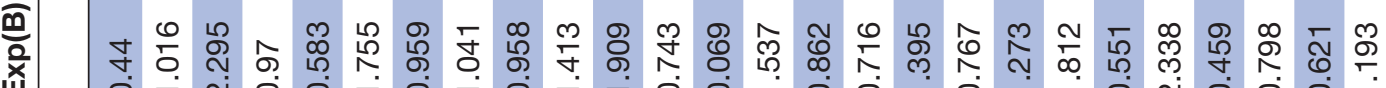
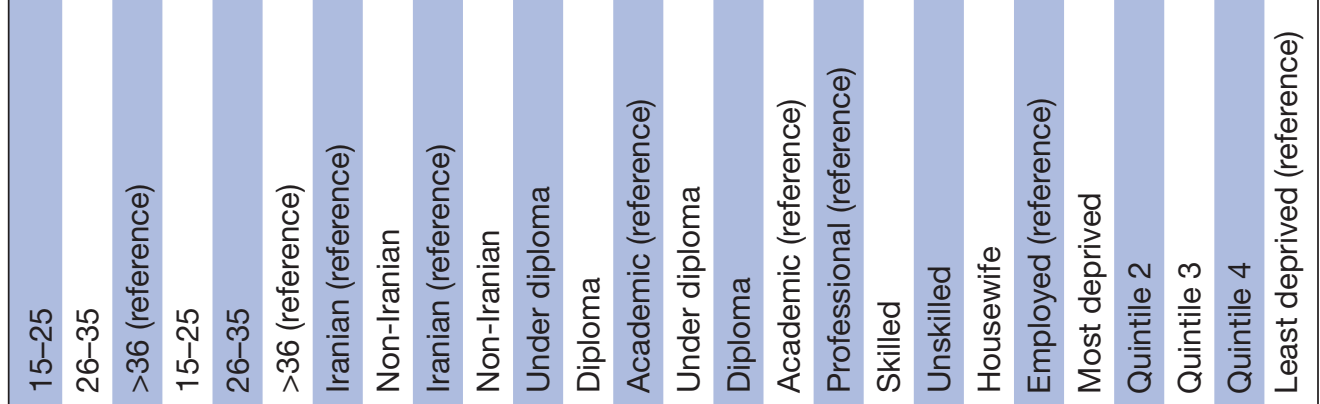

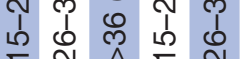

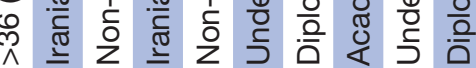

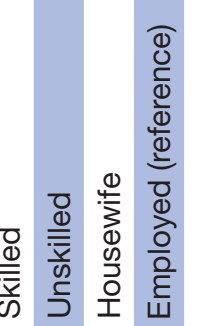




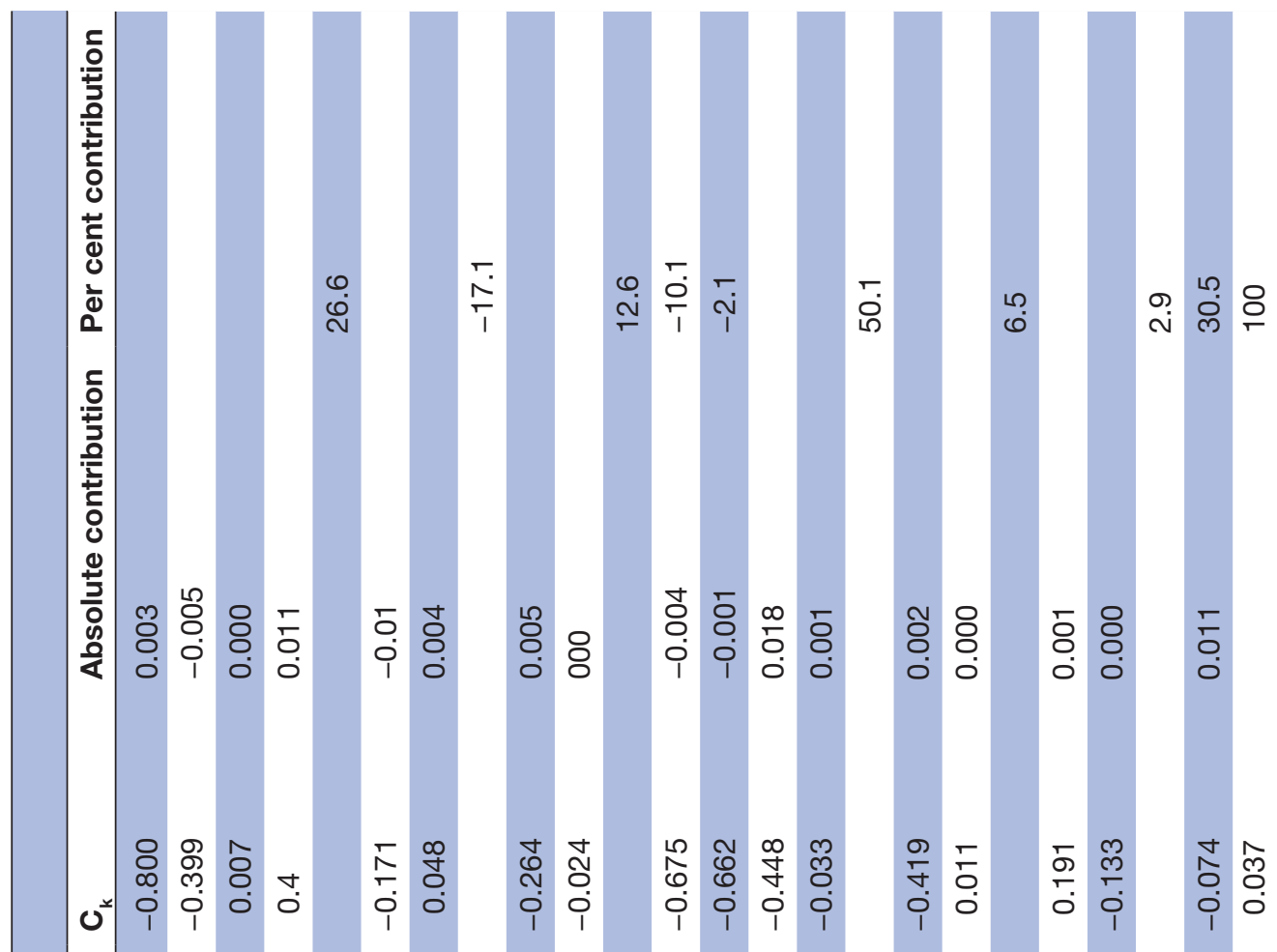

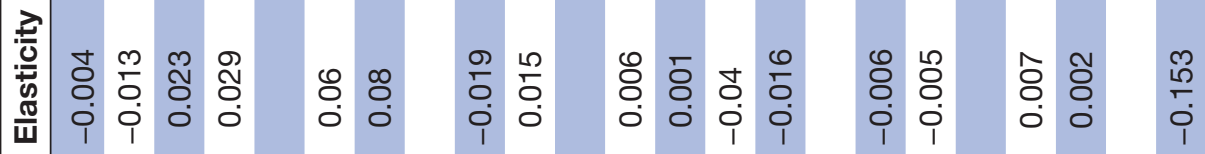

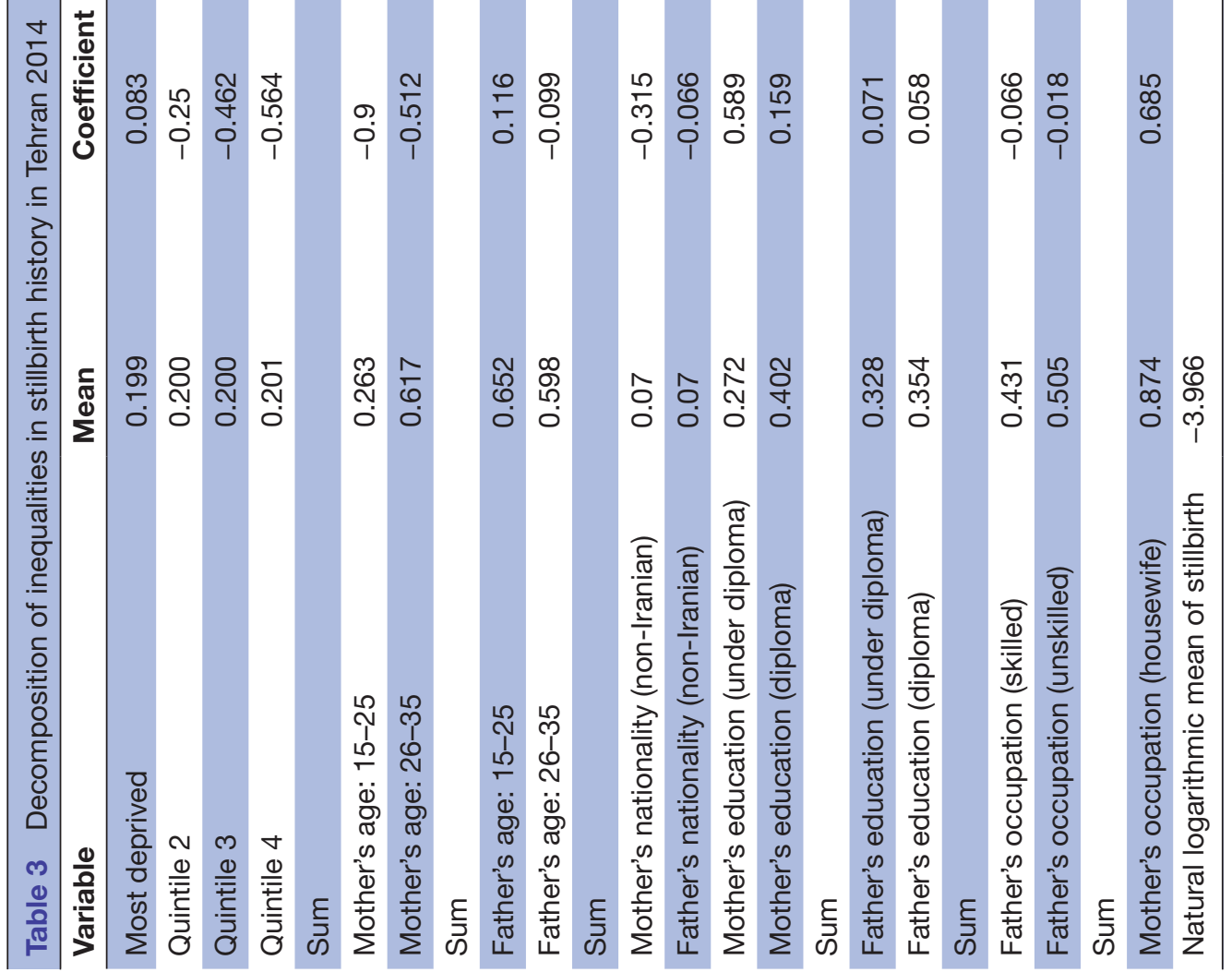

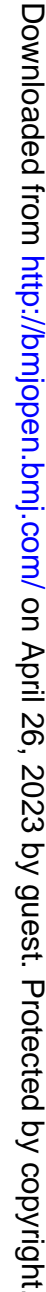


modifiable to some extent. Mother's education had the first high positive contribution to measured inequality such that under diploma and diploma educated mother were more likely to experience stillbirths compared with those having academic educations. A study by Savard $e t$ $a l$ in 2013 reported that absolute educational inequality in stillbirth persisted, and relative inequality increased over the past three decades, despite an overall decrease in stillbirth rates. The decrease in absolute inequality for placental abruption was countered by an increase for unspecified causes. ${ }^{31}$ These findings are also confirmed by global and semiglobal studies. ${ }^{13} 2429$

The present study also showed that maternal age older than 35 years is a protective factor for stillbirth and has negative contribution to the so-called inequality in stillbirth history. Contrary to the findings, a systematic review on maternal age and risk of stillbirth showed that women with advanced maternal age have an increased risk of stillbirth. However, the magnitude and mechanisms of the increased risk are not clear, and prospective studies are warranted. ${ }^{32}$ Another study on Iranian women showed that the odds of stillbirth were lower in women older than 38 years and higher in women aged 20-33 years old compared with those aged 34-37 years old, which shows that the odds of stillbirth do not increase linearly, and interpretation of the findings should be cautious. ${ }^{33}$ The current study also showed that paternal age older than 35 years is a protective factor for stillbirth and has negative contribution to the explained inequality in stillbirth history. As one of the limitations, the current socioeconomic status was measured as since it was believed that socioeconomic status could not be changed dramatically in the near past during stillbirth. A multisite population-based case-control study conducted on American women found the odds of stillbirth higher among those with paternal age $\geq 35$ years and $<20$ years compared with the subjects with paternal age between 20 and 34 years old, implying that the odds of stillbirth do not increase linearly, and interpretation of the findings should be cautious. ${ }^{34}$ As a relatively new finding, stillbirth among Iranian is more prevalent compared with non-Iranian women, the reason for which should be studied in future studies.

\section{CONCLUSION}

In conclusion, stillbirth is unequally distributed among Iranian women and is mostly concentrated among low economic status people. Mother-related factors had the highest positive and negative contributions to inequality. This matter calls for specific interventions for mothers to redress inequality. In other words, the mother-related factors are more modifiable than economic status to decrease socioeconomic inequality in stillbirth, and focusing on these factors would be more beneficial.

Acknowledgements This nationwide survey was conducted in Iran with the cooperation of the Royan Institute.
Contributors AAH, MS and ROS designed the study and were involved in data collection. SS, AAH, YS and MS participated in statistical analysis and drafted the manuscript. Critical revision was done by AAH, MS, SS, YS and ROS.

Competing interests None declared.

Ethics approval Ethical Committee of Royan Institute.

Provenance and peer review Not commissioned; externally peer reviewed.

Data sharing statement № additional data are available.

Open Access This is an Open Access article distributed in accordance with the Creative Commons Attribution Non Commercial (CC BY-NC 4.0) license, which permits others to distribute, remix, adapt, build upon this work non-commercially, and license their derivative works on different terms, provided the original work is properly cited and the use is non-commercial. See: http://creativecommons.org/ licenses/by-nc/4.0/

(c) Article author(s) (or their employer(s) unless otherwise stated in the text of the article) 2017. All rights reserved. No commercial use is permitted unless otherwise expressly granted.

\section{REFERENCES}

1. Khademi A, Alleyassin A, Amini M, et al. Evaluation of sexual dysfunction prevalence in infertile couples. J Sex Med 2008;5:1402-10.

2. Zarei S, Memari AH, Moshayedi P, et al. Psychometric properties of physical activity and leisure motivation scale in Farsi: an international collaborative project on motivation for physical activity and leisure. Arch Iran Med 2016;19:704-10.

3. Cousens S, Blencowe H, Stanton C, et al. National, regional, and worldwide estimates of stillbirth rates in 2009 with trends since 1995: a systematic analysis. Lancet 2011;377:1319-30.

4. World Health Organisation. The neglected tragedy of stillbirths. 2015

5. Lawn JE, Blencowe $\mathrm{H}$, Waiswa $\mathrm{P}$, et al. Stillbirths: rates, risk factors, and acceleration towards 2030. Lancet 2016;387:587-603.

6. Luque-Fernández MÁ, Lone NI, Gutiérrez-Garitano I, et al. Stillbirth risk by maternal socio-economic status and country of origin: a population-based observational study in Spain, 2007-08. Eur J Public Health 2012;22:524-9.

7. Stephansson O, Dickman PW, Johansson AL, et al. The influence of socioeconomic status on stillbirth risk in Sweden. Int J Epidemiol 2001;30:1296-301.

8. Heazell AE, Siassakos D, Blencowe H, et al. Stillbirths: economic and psychosocial consequences. Lancet 2016;387:604-16.

9. Seaton SE, Field DJ, Draper ES, et al. Socioeconomic inequalities in the rate of stillbirths by cause: a population-based study. BMJ Open 2012;2:e001100.

10. Lawn JE, Gravett MG, Nunes TM, et al. Global report on preterm birth and stillbirth (1 of 7): definitions, description of the burden and opportunities to improve data. BMC Pregnancy Childbirth 2010;10:S1.

11. Lawn JE, Lee AC, Kinney M, et al. Two million intrapartum-related stillbirths and neonatal deaths: where, why, and what can be done? Int J Gynaecol Obstet 2009;107:S5-S19.

12. Hofmeyr GJ, Haws RA, Bergström S, et al. Obstetric care in lowresource settings: what, who, and how to overcome challenges to scale up? Int J Gynaecol Obstet 2009;107:S21-S45.

13. Flenady V, Koopmans L, Middleton $P$, et al. Major risk factors for stillbirth in high-income countries: a systematic review and metaanalysis. Lancet 2011;377:1331-40.

14. Collins JH. Umbilical cord accidents: human studies. Semin Perinatol 2002;26:79-82.

15. Sepidarkish M, Almasi-Hashiani A, Maroufizadeh S, et al. Association between previous spontaneous abortion and preeclampsia during a subsequent pregnancy. Int J Gynaecol Obstet 2017;136.

16. O'Donnell OA, Wagstaff A. Analyzing health equity using household survey data: a guide to techniques and their implementation. World Bank Publications 2008.

17. Vyas S, Kumaranayake L. Constructing socio-economic status indices: how to use principal components analysis. Health Policy Plan 2006;21:459-68.

18. van Doorslaer E, Koolman X, Jones AM. Explaining incomerelated inequalities in doctor utilisation in Europe. Health Econ 2004;13:629-47.

19. Wagstaff A, Paci P, van Doorslaer E. On the measurement of inequalities in health. Soc Sci Med 1991;33:545-57. 
20. Wagstaff A, van Doorslaer E, Watanabe N. On decomposing the causes of health sector inequalities with an application to malnutrition inequalities in Vietnam. J Econom 2003;112:207-23.

21. Luque-Fernandez MA, Franco M, Gelaye B, et al. Unemployment and stillbirth risk among foreign-born and Spanish pregnant women in Spain, 2007-2010: a multilevel analysis study. Eur J Epidemiol 2013;28:991-9.

22. Stephansson O, Dickman PW, Johansson AL, et al. The influence of socioeconomic status on stillbirth risk in Sweden. Int J Epidemiol 2001;30:1296-301.

23. Jørgensen T, Mortensen LH, Andersen AM. Social inequality in fetal and perinatal mortality in the Nordic countries. Scand J Public Health 2008;36:635-49.

24. Blencowe $\mathrm{H}$, Cousens $\mathrm{S}$, Jassir FB, et al. National, regional, and worldwide estimates of stillbirth rates in 2015, with trends from 2000 a systematic analysis. Lancet Glob Health 2016;4:e98-e108.

25. Speybroeck N, Konings P, Lynch J, et al. Decomposing socioeconomic health inequalities. Int J Public Health 2010;55:347-51.

26. Harper S, Lynch J. Commentary: using innovative inequality measures in epidemiology. Int J Epidemiol 2007;36:926-8.

27. Liverpool LSO, Winter-Nelson A. Asset versus consumption poverty and poverty dynamics in the presence of multiple equilibria in rural
Ethiopia. Washington DC, USA: International Food Policy Research Institute, 2010.

28. Howe LD, Galobardes B, Matijasevich A, et al. Measuring socioeconomic position for epidemiological studies in low- and middleincome countries: a methods of measurement in epidemiology paper. Int J Epidemiol 2012;41:871-86.

29. Flenady V, Wojcieszek AM, Middleton P, et al. Stillbirths: recall to action in high-income countries. Lancet 2016;387:691-702.

30. Wood AM, Pasupathy D, Pell JP, et al. Trends in socioeconomic inequalities in risk of sudden infant death syndrome, other causes of infant mortality, and stillbirth in Scotland: population based study. BMJ 2012;344:e1552.

31. Savard N, Auger N, Park AL, et al. Educational inequality in stillbirth: temporal trends in Québec from 1981 to 2009. Can J Public Health 2013;104:e148-e53.

32. Huang L, Sauve R, Birkett N, et al. Maternal age and risk of stillbirth: a systematic review. CMAJ 2008;178:165-72.

33. Hajian-Tilaki K, Esmaielzadeh S, Sadeghian G. Trend of stillbirth rates and the associated risk factors in Babol, Northern Iran. Oman Med $J$ 2014;29:18-23.

34. Group SCRNW. Association between stillbirth and risk factors known at pregnancy confirmation. JAMA 2011;306. 